\title{
Overuse and Underuse of English Concluding Connectives: A Corpus Study
}

\author{
Ronggen Zhang \\ Shanghai Publishing and Printing College, Shanghai, China
}

\begin{abstract}
The use of connectives has always been a tough nut to crack for Second Language Learners of English. For example, the use of English concluding connectives like "all in all, in conclusion, last but not least, eventually, and ultimately", appears to be especially problematic. The study shows that there are significant overuses of "all in all, in conclusion, and Last but not least" for Chinese learners on the one hand, and underuses of "eventually and ultimately" for them on the other hand. This may result from their lack of proper understanding of each concluding connective's functions in the discourse. The paper makes a study of the meaning and use of those English concluding connectives by studying BNC(British National Corpus) and SWECCL (Spoken and Written English Corpus of Chinese Learners), also using definitions, and examples from Collins COBUILD Dictionary, as well as comparing native speakers' use with that of Chinese learners' English.
\end{abstract}

Index Terms - concluding connectives, corpus, discourse marker

\section{INTRODUCTION}

Connectives are the glue that holds a text together. They join clauses together in a sentence, and they join sentences in a long piece of writing (accessed from www.paelv.edu.ar). Connectives don't have to be just one word. They can be phrases like 'in conclusion' or 'in the end'. Connectives have been called cohesive conjunctions (Halliday and Hasan, 1976), logical connectors (Quirk and Greenbaum, 1973), or metadiscoursal markers (Vande Kopple, 2002). In the literature on second language acquisition, the use of connectives has repeatedly been mentioned as a problem area for learners of English, regardless of their mother tongue (for example, Granger and Tyson, 1996; Silva, 1993). Overuse, under-use, and misuse have been reported, with overuse being the most predominant, leading to problems of coherence or readability of the discourse. Conversely, the skilful use of connectives has been identified as a hallmark of language proficiency, reflective of the stage of development of both native and non-native speakers' writing (Goldman and Murray, 1992; Johnson, 1992; Lorenz, 1997). It is not surprising, therefore, that connectives have remained an area of major concern, especially at an advanced stage of second language development. In commenting on the way forward, researchers (for example, Granger and Tyson, 1996; Lorenz, 1997) have emphasized the importance of not treating connectives in a wholesale fashion, but rather, investigating them individually to identify their various patterns of functions and meanings in L1, as compared with those in L2. To shed further light on learners' problems, it would also be essential to examine learners' inter-language to uncover problems either due to L1 transfer or language universals. At the same time, as a pedagogical aid, a good dictionary of connectives would be crucial (Granger and Tyson, 1996) (as cited in Yeung, 2009). In the past decade, more research has been done in uses of connectives. It is found that formfocused instruction with explicit semantic, stylistic and syntactic properties can help learning of connectives (Tseng and Liou, 2006). Bolden finds the discourse marker 'so' is a resource for establishing discourse coherence and, more fundamentally, accomplishing understanding (Bolden, 2009). Charles investigates connectives of result in the writing of advanced academic student writers, which finds the wider discourse context could provide a rationale for the choice of both the individual connective itself and the most appropriate phraseology (Charles, 2011).

In response to the above, this paper makes an attempt to study the concluding connectives, like "all in all, in conclusion, last but not least, eventually, and ultimately", which appears to be especially problematic. The study shows that there are significant overuses of "all in all, in conclusion, and Last but not least" for Chinese learners on the one hand, and under-uses of "eventually and ultimately" for them on the other hand. This may result from their lack of proper understanding of each concluding connective's functions in the discourse. The paper makes a study of the meaning and use of those English concluding connectives by studying BNC(British National Corpus) and SWECCL (Spoken and Written English Corpus of Chinese Learners), using definitions, and examples from Collins COBUILD Dictionary, as well as comparing native speakers' use with that of Chinese learners' English .

The concluding connectives are used to indicate that speaker is making final statements that cover all the supporting arguments in a very general way. The concluding connectives "all in all, in conclusion, last but not least, eventually, and ultimately "are typically overused or underused by Chinese learners. The existing literature gives little account of concluding connectives.

In the light of the above case, this study mainly focuses on the following points: 
a) The kind of problems that may appear when learners do not have the proper understanding of the use of the concluding connectives "all in all, in conclusion, last but not least, eventually, and ultimately" mentioned above.

b) The typical patterns of use of those connectives in standard English and their functions in English discourses.

c) Pedagogical implications of the findings.

\section{METHODOLOGY}

\section{A. Selection of Corpora}

\section{Experts' corpora}

The study is carried out through checking BNC (British National Corpus) and Collins COBUILD Dictionary on CDROM 2006(COBUILD), downloaded at random from the Internet.

2. Learners' corpus

The learner corpus SWECCL (Spoken and Written English Corpus of Chinese Learners) comprises Chinese learners' argumentative and expository essays (4,560,029 words).

\section{B. Analytical Methods}

1. Frequency count

A frequency count was made of the instances of use of "all in all, in conclusion, last but not least, eventually, and ultimately" in the native speakers' corpora. As there was a register difference in the native speakers' corpora, the genres in the corpora were noted for comparison with those in the learners' corpus (Yeung, 2009). The frequencies of occurrence of "all in all, in conclusion, last but not least, eventually, and ultimately" in the experts' and learners' corpora were also compared. Frequency of occurrence was taken as an indicator of the norm of usage in the respective corpora.

2. Discourse analysis

In the classical study on cohesion, Halliday and Hasan (1976) pointed out the pragmatic function of connectives in signaling a change in speech acts. Halliday and Hasan (1976) also stressed the importance of the surrounding text in the choice of the right connective. According to them, it is not the connectives themselves that reach out independently to bind the sentences together, but rather it is the particular discourse environment or the logic of the text that calls for the use of a particular connective (Yeung, 2009).

TABLE 1

\begin{tabular}{|c|c|c|c|c|c|c|c|c|}
\hline \multirow[b]{2}{*}{ Connective } & SWECCL & \multicolumn{7}{|c|}{ FREQUENCIES OF CONCLUDING CONNECTIVES IN SWECCL VS. BNC } \\
\hline & $\operatorname{Item}(\mathrm{s})$ & PER MIL & $\begin{array}{l}\text { Written } \\
\text { PER MIL }\end{array}$ & $\begin{array}{l}\text { Spoken } \\
\text { PER MIL }\end{array}$ & $\operatorname{Item}(\mathrm{s})$ & PER MIL & $\begin{array}{l}\text { Written } \\
\text { PER MIL }\end{array}$ & $\begin{array}{l}\text { Spoken } \\
\text { PER MIL }\end{array}$ \\
\hline Ultimately & 15 & 3.2895 & 3.0702 & 0.2193 & 2813 & 29.43 & 26.75 & 1.38 \\
\hline Eventually & 81 & 17.763 & 14.693 & 3.0702 & 8781 & 91.88 & 81.73 & 6.08 \\
\hline $\begin{array}{l}\text { Last but } \\
\text { not least }\end{array}$ & 133 & 29.166 & 26.096 & 3.0702 & 47 & 0.49 & 0.45 & 0.02 \\
\hline in conclusion & 220 & 48.245 & 44.298 & 3.9473 & 294 & 3.08 & 2.7 & 0.24 \\
\hline all in all & 377 & 82.675 & 77.192 & 5.4824 & 298 & 3.12 & 2.77 & 0.21 \\
\hline
\end{tabular}

\section{FINDINGS}

\section{A. Frequencies Compared}

The table shows, there exist vast differences of frequencies of the concluding connectives between the Chinese learners and the native speakers. Obviously, there are significant overuses of "all in all, in conclusion, and Last but not least" for Chinese learners, where the frequencies of them among per million tokens respectively are 82.675, 48.245, and 29.166 in SWECCL, compared with 3.12, 3.08, and 0.49 in BNC. On the other hand, there are under-uses of "eventually and ultimately" for Chinese learners, where the frequencies of them among per million tokens respectively are 17.763 and 3.2895, compared with 91.88 and 29.43 in BNC. The discourse analysis below will explain why the Chinese learners overuse or under-use those connectives.

\section{B. Discourse Patterns of Use: Use of "All in All, in Conclusion, Last But Not Least, Eventually, or Ultimately", as a Connective in the Learners' Corpus vs. BNC and COBUILD.}

In COBUILD, "all in all" is defined to be used to introduce a summary or general statement.

Example 1

All in all, it is a pretty unconvincing picture.

If you say that children are completely non-rational then you have to account for the fact that they become rational, and to do that it appears from these examples that you have to assume that they already are.

Example 2 
All I wish to do here is to suggest that there are other ways of understanding or looking at extremes of penitential life which can suggest in them sources, not of neurotic repression but of freedom and self-ownership.

All I would be was a punchbag for his escaping fury, the entity he saw as a new unbearable threat to his dominance in Tremayne's stable; the interloper, usurper, legitimate target.

All in a flurry of dust it came towards her and then she heard Ferdinando shout her name and the neighing of the horse as it was pulled in and she trembled as she opened her eyes and looked up.

All in all, it's more difficult to evaluate an actor's work on screen, particularly as actors are usually cast in a film for their total credibility in a role and the camera work is such an intrinsic part of the final effect.

All in all, it is submitted that the claim that there is a risk of liability under section 2 of the Suicide Act does not serve as a valid justification for ignoring the request of the patient that treatment be discontinued.

All in all, it seems to have diverted De Niro's energies away from the more serious and interesting business of Tribeca Productions, and in future, it may even start to eat into company funds (accessed from www.cis.hut.fi).

All in all, the entire Labour package is a massive con-trick, which a sinister shadow cabinet, behind its smiling mask of reassurance, is even now preparing to abandon under the narcotic influence of power.

Example 1 and 2 are from BNC. In example 1, "all in all" is used to introduce a general statement, while in example 2 , the four repeated occurrences of "all in all" are for emphatic purposes, equivalent to "after all".

Example 3

All in all, I believe that the function of university education is more to promote one's important of quality than to find a well-paid job. And with all these function, our college students will be have a fruitful life and successful career in future.

Like example 3 in SWECCL, it seems to show that almost every connective of "all in all" is used to introduce a summary rather than a general statement or to emphasize some point.

In COBUILD, "In conclusion" is defined to be used to indicate that what you are about to say is the last thing that you want to say.

Example 4

The charges can not leave the wire so they will accumulate at the outer and inner surface of the ring until a radial electric field is produced that will cancel the force due to the magnetic field.

In conclusion, I wish to emphasize that all the charge rearrangements discussed in this section occur very fast, much faster than the period of oscillation of the magnetic field.

Example 4 from BNC indicates that "in conclusion" is used to finish what the speaker wants to say.

Example 5

In conclusion, university education is not only to prepare for employment. It also provides us a lot of other useful things we need to learn.

Example 5 from SWECCL indicates that "in conclusion" is used to summarize what the speaker has said.

In COBUILD, "last but not least" is defined to be used to say that the last person or thing to be mentioned is as important as all the others.

Example 6

Interested listeners might look to the less renowned record labels, such as Capriccio in Germany, which has issued a superb recording of Mozart songs by Mitsuko Shirai, a soprano, and her pianist-husband Hartmut Hoell. And, last but not least, they might re-read the scores while listening. Perhaps the most laudable project of the Mozart bicentenary is the publishing by Baerenreiter Verlag in Kassel of the complete musical scores in paperback, a 20 volume set at a reasonable price. Unlike any interpretation, however persuasive, the notes on the page are, after all, what the man wrote (accessed from http://corpus.byu.edu/bnc/).

Example 6 from BNC indicates that "last but not least" is used to emphasize what the writer will say in the end is as important as what he said before: the listeners should re-read the scores while listening to the recording.

Example 7

In conclusion, may I take this opportunity of thanking the Chief Executive and Directors of Plantsbrook Group, the National Secretary, the Officers, Administration Secretary and the Staff at the National Office and, last but not least, my colleagues at work for all their support during the past twelve months.

Example 7 from BNC indicates that "last but not least" can not only be placed before a clause like in example 6, but also before a word group.

Example 8

So reading skill can improve your speaking indirectly in this way. Last but not the least, reading, somehow can be your own business, so it's a convenient way for you to communicate with yourself without being disturbed.

Example 8 from SWECCL indicates that "last but not least", placed at the beginning of the last sentence of a passage, is used to emphasize that the last item is as important as the previous items.

In COBUILD, "eventually" is defined to mean "in the end", especially after a lot of delays, problems, or arguments.

Example 9 
From, from Yugoslavia, and we, we heard provisionally he was released about August didn't we, and then eventually a couple of months ago that he had definitely released, erm, and, were, were very pleased about that cos was he released before the end of his term, he must have been?

Example 9 from BNC indicates "eventually" meaning after "a couple of months' delays" he was released in the end.

Example 10

Apparently, KFC are developing much better than MacDonald's during one decade. KFC gradually expand its shops in large rate, which eventually make it domain the fast-food market of China. To the contrary, KFC's opponent, MacDonald's seems put not much priority on China market. Its smaller investment make it lost the domain of the market it should have obtained as what it has done in the USA.

Example 10 from SWECCL indicates "eventually" meaning the end of a situation, i.e. after solving a lot of problems KFC dominates the fast-food market of China.

In COBUILD, "ultimately" is defined: first, to mean finally, after a long and often complicated series of events.; and second, to indicate that what you are saying is the most important point in a discussion.

Example 11

As the audience take their seats for "Pamela" we can hear, from the onstage tannoy, stage management calls and, ultimately, an announcement: "Ladies and Gentlemen, please take your seats in the main auditorium; this afternoon's performance of "Coriolanus" is about to begin." As the music and dialogue of the offstage production begin, a member of the "Pamela " cast turns the volume off (accessed from http://corpus.byu.edu/bnc/).

"Ultimately" in example 11 from BNC means a long and often complicated series of events, i.e. the audience can hear stage management calls and, ultimately, an announcement.

Example 12

Public Relations is, ultimately, everyone's responsibility. everybody involved -- especially those in day to day contact with \# 58B \# potential customers -- must be AWARE of the effect their appearance, and that of the site, their manner and behaviour has on these very important people. Some are born ambassadors -- others need tuition. \# 58C \# WHEN the work is complete, some Regions take the trouble to invite local dignitaries to come and cut the proverbial tape. This is a great idea -- why don't we do it

"Ultimately" in example 12 from BNC means what the speaker is saying is the most important point in a discussion, i.e. Public Relations is, ultimately, everyone's responsibility.

Example 13

To sum up, education is a lifelong process. It could render us a stronger sense of security, ultimately bringing to us a healthy and blessed life, and thus is a advisable choice

"Ultimately" in example 13 from SWECCL means finally, after a long series of events, i.e. work hard, keep on learning, and so on, it will bring to us a healthy and blessed life.

\section{ANALYSIS}

\section{A. Pragmatic Functions of "Concluding Connectives" -Learners' And Experts' Corpora Compared}

In general, learners use the concluding connectives like "all in all, in conclusion, last but not least, eventually, and ultimately", in ways which deviate from the ones identified in the expert corpus. Such deviations can be summarized as follows:

a) Use of "all in all" is used to introduce a summary rather than introduce a general statement or emphasize some point.

b) Use of "in conclusion" is used to summarize what the speaker has said rather than what the speaker wants to say.

c) Use of "last but not least" is used to emphasize that the last item is as important as the previous items rather than to say that the last person or thing to be mentioned is as important as all the others.

d) Use of "eventually" meaning the end of a situation after solving a lot of problems rather than after a lot of delays, problems, or arguments.

e) Use of "ultimately" is used to mean "finally", after a long series of events rather than to indicate that what the speaker is saying is the most important point in a discussion.

From the above, it seems that a lack of awareness of how each concluding connective functions as a discourse marker can lead to learners' overuse and under-use of the connective

\section{B. The Question of L1 Transfer}

There appear to be several reasons for the learners' ineptness in using the concluding connectives. Direct language transfer from what is known as a "false friend" (James, 1998) in their first language seems to be the least important. Developmental problems, which are more universally shared, appear to be far more important (Yeung, 2009).

Some Chinese learners may just translate literally their connectives from Chinese into English, which may lead to overuse or under-use of some connectives. For instance, the Chinese connective expression "zǒng zhı̈" may be misleadingly translated as "in conclusion", "zhōng yú" as "eventually", and "zuì hòu" as "Ultimately". 
"Last but not least" has become a cliché in Chinese learners' writings, which may result from their imitations of some writing templates given by the teachers in the test training courses such as CET-4(College English Test Band 4), CET-6(College English Test Band 4), IELTS, etc.

\section{PEDAGOGiCAL IMPLiCATIONS}

\section{A. Register}

As far as register is concerned, the Chinese learners differ a little from the native English speakers in using concluding connectives. For instance, "eventually" is used rather frequently by Chinese learners in informal style while native speakers use it mostly in formal style. And "Last but not least" is used rather often by Chinese learners both in formal and informal style, while it is rarely used by native speakers. Hence, the learners need to be shown the difference in register when using the connectives.

\section{B. Pragmatic Functions of Connectives}

From the definitions of connectives given by COBUILD, we know that concluding connectives like "all in all, in conclusion, last but not least, eventually, and ultimately" have very distinct pragmatic functions. Some is used to introduce a summary, yet some to emphasize, to indicate end of a situation, or to express a long series of events, and the like. And the Chinese learners may feel confused about such differences in meanings of the connectives. To solve the problem, the learners should be given adequate authentic examples in both ELT textbooks and the ELT classroom. They are to be encouraged to read more original English periodicals, books, and so on, to form their own sense of English language. .

\section{Overuse and Underuse}

To solve the problems of overuse and under-use, learners should be made to realize that logical connectors are only required when a relationship between ideas is not apparent in the discourse. For this purpose, alternative versions of the same text with and without connectives can be used for a comparative study of how redundancy can be avoided (Yeung, 2009). Learners should also be shown that apart from connectives, there are other methods of giving a text the necessary cohesion, that is, applying syntactic device like ellipsis or lexical device like synonym. A proper understanding of thematic development in continuous texts would also be essential (Yeung, 2009). Proper paragraphing presents yet another way of getting rid of redundant concluding connectives such as "Last but not least":

Example 14

Last but not least, cooperation is based on party. Learn to cooperate is learn to work with others. Power of a party is more powerful than a single one's. As known to all, learn to live harmonious with others are the most factors for one to suit the society.

To sum up, competition is bad for children are shaping of their philosophy, and even bad for developing for society. But cooperation will lead a right way for children to grow up. So children should learn to cooperate.

'Last but not least' in Example 14 from SWECCL, for instance, is replaced by another concluding phrase "To sum up", which previews the rest of the paragraph, turning into a separate transitional paragraph. Each subsequent section foreshadowed by the transitional paragraph can be made a paragraph on its own, thus avoiding the need for an exhaustive use of all the available concluding connectives. To gain an accurate sense of the use of other cohesive devices, learners should work with authentic texts which clearly show that each paragraph need not begin with a connective to show they are related to one another and to the whole (Yeung, 2009).

\section{CONCLUSION}

This study has attempted to distinguish the functions and patterns of concluding connectives like "all in all, in conclusion, last but not least, eventually, and ultimately" in both experts' and learners' corpora. Distinctive characteristics have been described and differences in patterns of use between the expert and learner writers have been singled out for comparison. Similar to Yeung's findings (Yeung, 2009), concluding connectives are also found to be a tough nut to crack in second language acquisition, not only to Chinese learners of English, but non-native learners from various linguistic backgrounds as well. The study shows that concluding connectives should be understood not only in terms of their semantic meanings but are better grasped through an understanding of their pragmatic and stylistic functions in actual contexts of use. As the case of concluding connectives like "all in all, in conclusion, last but not least, eventually, and ultimately" shows, traditional ways of teaching and learning concluding connectives, as well as the traditional approaches adopted by many a teaching and learning tool such as dictionaries and ELT textbooks, seem to be renovated, i.e. learners are to be encouraged to read more original English periodicals, books, and the like.

\section{REFERENCES}

[1] Bolden, Galina B. (2009). Implementing incipient actions: The discourse marker 'so' in English conversation. Journal of Pragmatics, 41, 974-998.

[2] BRITISH NATIONAL CORPUS (no date). http://corpus.byu.edu/bnc/ (accessed 21/2/2013). 
[3] Charles, Maggie. (2011). Adverbials of result: Phraseology and functions in the Problem-Solution pattern. Journal of English for Academic Purposes, 10, 47-60.

[4] Chinese Learner English Corpus (no date). http://www.clal.org.cn/corpus/EngSearchEngine.aspx (accessed 29/12/2012).

[5] Goldman, S.R. Murray, J., (1992). Knowledge of connectors as cohesion devices in text: a comparative study of native-English and English-as-a-second-language speakers. Journal of Educational Psychology 83, 504-519.

[6] Granger, S., Tyson, S. (1996). Connector usage in the English essay writing of native and non-native EFL speakers of English. World Englishes 15, 17-27.

[7] Halliday, M.A.K., Hasan, R. (1976). Cohesion in English. London: Longman.

[8] Johnson, P. (1992). Cohesion and coherence in compositions in Malay and English. RECL Journal 23, 1-17.

[9] Lorenz, G. (1997). Learning to cohere: causal links in native vs non-native argumentative writing. In S. Bublitz, U. Lenk, \& E.Ventola (Eds.), Coherence in Spoken and Written Discourse: How to Create it and How to Describe it, Selected Papers from the International Workshop on Coherence. Amsterdam: John Benjamins Publishing Co., 55-75.

[10] Quirk, R., Greenbaum, S. (1973). A University of Grammar of English. London: Longman.

[11] Silva, T. (1993). Towards an understanding of the distinctive nature of L2 writing: the ESL research and its implications. TESOL Quarterly 27, 657-677.

[12] Tricas, Mercedes (1991). L'argumentation concessive francaise et espagnole. Meta 35, 529-537.

[13] Tseng, Y., Liou, H. (2006). The effects of online conjunction materials on college EFL students' writing. System, 34, $270-283$.

[14] Vande Kopple, W.J. (2002). Metadiscourse, discourse and issues in composition and rhetoric. In E. Barton \& G. Stygall (Eds.), Discourse Studies in Composition. Cresskill, NJ: Hampton Press, 91-113.

[15] Yeung, L. (2009). Use and misuse of 'besides': A corpus study comparing native speakers' and learners' English, System 37, $330-342$.

[16] www.cis.hut.fi (accessed 21/2/2013).

[17] www.paelv.edu.ar (accessed 21/2/2013).

Ronggen Zhang, Associate professor, holds a MA degree in ESP from University of Shanghai for Science and Technology in China. His research interest lies in corpus linguistics and investigation of language teaching strategies. He is now teaching in Shanghai Publishing and Printing College. He has recently published in JCIT (Journal of Convergence Information Technology). 